\title{
MAPEAMENTO DE CICATRIZES DE ESCORREGAMENTOS UTILIZANDO IMAGEM MULTIESPECTRAL
}

\author{
Tiago Damas Martins ${ }^{1}$ \\ Chisato Oka-Fiori ${ }^{2}$ \\ Bianca Carvalho Vieira ${ }^{3}$
}

RESUMO: O mapeamento de cicatrizes de escorregamentos integra o inventário destes fenômenos a partir de diferentes técnicas. Entretanto, a literatura não apresenta procedimentos específicos para sua realização, sobretudo na classificação entre a área que sofreu a ruptura e a área de "passagem e arraste" do material transportado. Este trabalho objetivou apresentar e discutir um procedimento de mapeamento de cicatrizes baseado em imagens de satélite, que possa contribuir em uma melhor definição de critérios/normas para o mapeamento destas feições. Foram selecionadas duas bacias hidrográficas com ocorrência de cicatrizes dos escorregamentos de 2011. Dentre os testes, o de correlação de bandas pela operação Band Ratio apresentou o melhor resultado. Contudo, mesmo que a resolução da imagem possibilite a identificação visual da cicatriz, não permitiu uma clara definição dos seus limites e do material transportado/depositado, sendo adequado apenas para aplicações em escala até 1:25.000. Destaca-se que não foi possível determinar um critério de delimitação de uma cicatriz, que pode: a) incluir apenas a área de deslocamento de material, ou b) incluir a área fonte do material e toda a área afetada pelo seu percurso.

Palavras-chave: cicatrizes de escorregamentos; serra do mar do Paraná, sensoriamento remoto.

\section{MAPPING LANDSLIDES SCARS USING MULTISPECTRAL IMAGE}

ABSTRACT: Mapping of landslide scars integrates inventory of these phenomena based on different techniques. However, the literature does not provide specific procedures for its implementation, especially in the classification of the areas that suffered rupture and the area of "passage and drag" of the transported material. This study aimed to present and discuss a procedure to map a landslide scar using satellite imagery, in order to contribute for a better definition of criteria/standards to map these features. It was selected two watersheds with occurrence of landslides scars from 2011. Among the tests, the correlation of bands by operation Band Ratio showed the best result. However, even if the image resolution allows visual identification of the scar does not allow clear definition of its limits and transported/deposited material and is only suitable for applications at 1:25,000 scale. It is noteworthy that it was not possible to define criteria to delineate the scar, which may: a) include only the area of material displacement, or $b$ ) include the source area of the material and the entire area affected by its route.

Keywords: landslide scar; serra do mar of Paraná, remote sensing

1. Programa de Pós-Graduação em Geografia - UFPR (martins.td@gmail.com).

2. Programa de Pós-Graduação em Geografia - UFPR (chisato@ufpr.br).

3. Departamento de Geografia - USP (biancacv@usp.br). 


\section{INTRODUÇÃO}

Os movimentos de massa são fenômenos recorrentes na paisagem e podem ser definidos como um processo exogenético caracterizado como transporte de material, pela força gravitacional, com ou sem ajuda de água corrente como agente de transporte, e podendo ocorrer de maneira rápida ou lenta (CROZIER, 1986).

A partir da análise de eventos de movimentos de massa foram propostas diferentes classificações que consideram características do tipo de material deslocado, velocidade e a sua morfometria. Além da classificação, os fatores intrínsecos como as propriedades físicas das encostas, bem como agentes deflagradores, tanto naturais quanto induzidos são também contemplados para a análise destes fenômenos. Para um maior aprofundamento sobre o tema, podem ser verificados, dentre outros, os trabalhos de Hutchinson (1968), Zaruba e Mencl (1976), Varnes (1978), Guidicini e Nieble (1983) e Augusto Filho (1992).

A ocorrência de um evento de movimento de massa, em especial os escorregamentos, deixa evidências marcadas na paisagem que são definidas como cicatrizes (Figura 01). 0 mapeamento das cicatrizes integra o inventário destes fenômenos utilizando diferentes técnicas, dependendo dos objetivos da pesquisa (GUZZETTI et al., 2012).

Os autores fizeram uma revisão crítica dos métodos e ferramentas, convencionais e recentes, para preparar mapas e inventários em diferentes escalas (1:5.000 - 1:500.000), destacando suas principais funções: a) documentar os deslizamentos em diferentes escalas (pequenas áreas, regiões e países); b) etapa preliminar da avaliação de risco, suscetibilidade ou perigo; c) investigar a distribuição e os tipos de deslizamentos em relação à Geomorfologia/Geologia e d) estudar a evolução da paisagem dominadas por estes processos (GUZZETTI et al., 2012).

Portanto, nos inventários são identificados e localizados os deslizamentos por meio de interpretação de fotografias aéreas ou imagens de satélites, visitas de campo, dados históricos etc. A localização espacial, juntamente com outras informações relevantes sobre o processo (ex. tipologia, forma, tamanho, raio de alcance e volume de material deslizado), subsidia, na maioria das vezes, os demais métodos, por fornecer um registro dos processos ocorridos no passado e no presente. Tais informações, segundo Fernandes e Amaral (1996), são, comumente, utilizadas na modelagem física dos processos, contribuindo para o entendimento dos processos e sua distribuição espaço-temporal.

O desenvolvimento de inventários contribui, mormente, em estudos de suscetibilidade, vulnerabilidade, perigo ou risco (GUZZETTI et al., 2012), sendo, portanto, uma etapa primária para estudos de ocorrência de movimentos de massa utilizando diferentes técnicas (VAN WESTEN, 1993). Nas análises de frequência da ocorrência do fenômeno, o inventário permite correlações entre o registro dos deslizamentos pretéritos em uma determinada área e os fatores condicionantes, tais como estruturas litológicas e topográficas (GUTHRIE, 2002; AVANZI, et al., 2004), o tipo de uso (LEE, et al., 2002; PEROTTO-BALDIVIEZO et al., 2004) e o mecanismo deflagrador específico (GUNS e VEERLE, 2014).

Diante do exposto, o mapeamento das cicatrizes se apresenta como uma etapa fundamental e imprescindível para elaboração do inventário. Dentre as principais vantagens destes mapas estão: a simplicidade para sua execução, a análise da distribuição dos deslizamentos na paisagem, a fácil ou possibilidade imediata de integração com fatores condicionantes e a 
utilização como ferramenta para validação de produtos da modelagem matemática (VAN WESTEN, 2004; GUZZETTI et al., 2012)

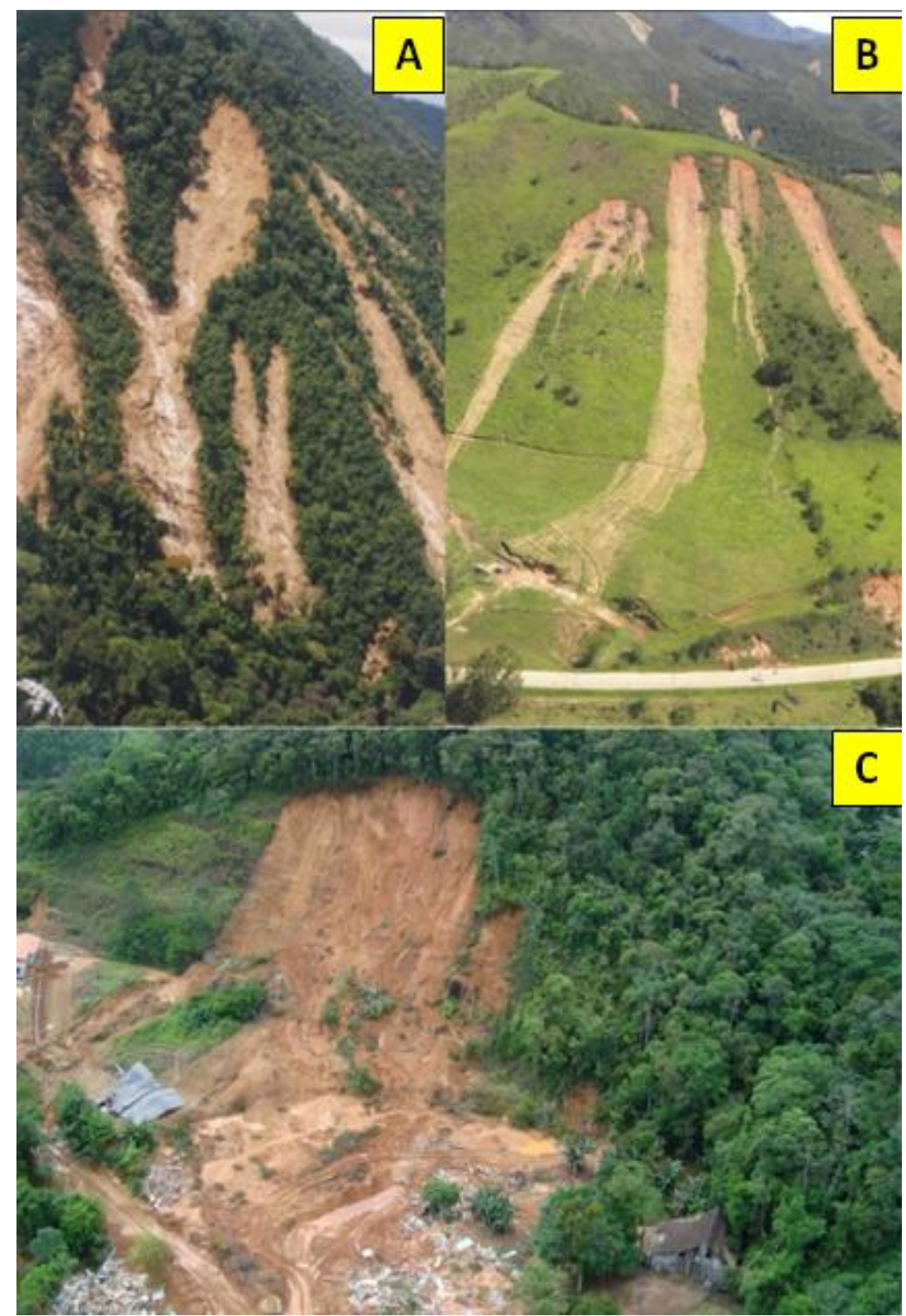

FIGURA 01: Cicatrizes de escorregamentos considerando suas zonas de ruptura, arraste e deposição. (A) Maciço da Tijuca (RJ)/1996; (B) Região Serrana do RJ/2011 e (C) Santa Catarina/2008.

Foto: (A) Fundação Georio (1996), (B) Bianca Carvalho Vieira e (C) Marcelo Gramanni (2008).

Não obstante, a literatura não traz procedimentos específicos a serem adotados para realização de um inventário definitivo e de como validar um mapa de cicatrizes, o que virá a depender de cada estudo (GUZZETTI et al., 2012). Assim sendo, a definição da área da cicatriz ainda é um desafio, devido, sobretudo, à diferença entre a área de ruptura e as "zonas de passagem e de arraste". 
No Brasil, diferentes trabalhos executaram mapeamento de cicatrizes com intuito de validar modelos preditivos, tais como Guimarães et al. (2003), Zaidan e Fernandes (2009) e Silveira et al. (2012).

Guimarães et al. (2003) e Zaidan e Fernandes (2009) aplicaram o modelo matemático SHALSTAB (Shallow Landsliding Stability Model) que calcula a suscetibilidade a escorregamentos translacionais rasos, em escala de bacia hidrográfica, a partir da compilação de um modelo de estabilidade baseado na Equação do Talude Infinito, e de um modelo hidrológico (steady-state), que são combinados para determinar uma razão entre quantidade de chuva e transmissividade do solo suficiente para ocorrência de um escorregamento.

Guimarães et al. (2003) aplicaram o modelo em duas bacias de drenagem no município do Rio de Janeiro (RJ), afetadas por inúmeros escorregamentos rasos em 1996. Após validação dos resultados utilizando o mapa de cicatrizes, identificaram que $79 \%$ das 92 cicatrizes coincidiram com as três classes mais instáveis e que a coesão do solo e os parâmetros topográficos (ângulo da encosta e área de contribuição) influenciaram na previsão de áreas potencialmente instáveis.

Já Zaidan e Fernandes (2009), no intuito de definir áreas suscetíveis a escorregamentos utilizaram o SHALSTAB na Bacia Hidrográfica do Córrego Independência, que se estende pela área urbana do município de Juiz de Fora (MG). Como procedimento de validação os autores mapearam as cicatrizes de possíveis movimentos de massa (pretéritos) por meio de interpretação fotogramétrica. Verificaram um alto índice de correlação (100\%) entre as classes instáveis ou incondicionalmente instáveis do modelo com as cicatrizes mapeadas.

Apoiando-se do Fator de Segurança, Silveira et al. (2012) realizaram uma análise da estabilidade das vertentes na Bacia Hidrográfica do Rio Jacareí, entre no município de Morretes e Paranaguá (Paraná), uma área profundamente afetada por movimentos de massa em 2011. Os resultados foram validados usando o mapa de cicatrizes e mostraram que as classes com muito alta susceptibilidade coincidiram em $81 \%$ com as cicatrizes mapeadas.

Nestes trabalhos nacionais, assim como em artigos internacionais, foram aplicados diferentes métodos para o mapeamento das cicatrizes, sobremaneira utilizando ortofotos. Tal mapeamento foi feito com base em análise visual das feições, adotando-se alguns critérios tais como a sua geometria, a ausência da vegetação, a análise textural e a posição na encosta. Esse último critério é bastante utilizado em trabalhos na Serra do Mar que mostram que as rupturas dos escorregamentos ocorrem na porção ou terço superior da cicatriz (zona de ruptura). As demais porções são consideradas zonas de transporte/arraste e de deposição do material.

Sendo assim, o mapa de cicatrizes é uma importante ferramenta para compreender a espacialização e alguns fatores condicionantes dos movimentos de massa. Entretanto, a delimitação exata destas cicatrizes, sobretudo a zona de ruptura, não é uma tarefa fácil, pois são raros os trabalhos específicos sobre o mapeamento, não havendo, portanto, critérios ou normas bem definidas para a delimitação das zonas de ruptura, de arraste e de deposição. Assim, este trabalho tem como objetivo apresentar um procedimento de mapeamento de 
cicatrizes a partir de imagens de satélite, tentando contribuir definição de critérios/normas destes mapeamentos.

\section{- Serra do mar e o município de Antonina}

O estado do Paraná possui uma compartimentação do relevo marcada, de Leste para Oeste, pela planície litorânea, a Serra do Mar, e planaltos interiores - Primeiro, Segundo e Terceiro (MAACK, 1947 e 1981; SANTOS et al., 2006).

Esta divisão traz destaque a barreira formada pela Serra do Mar, uma serra marginal originada por escarpamento de falhas e abatimentos de blocos com direção predominante NE e NNE e que limita as terras baixas do litoral a leste, dos planaltos interiores a oeste (MAACK, 1947 e 1981; ALMEIDA e CARNEIRO, 1998; SANTOS et al., 2006; GONTIJOPASCUTTI et al., 2012). A composição fitogeográfica tem na Floresta Ombrófila Densa seu maior destaque, ocorrendo associações vegetacionais determinadas pela variação altimétrica do relevo (RODERJAN et al., 2002).

O quadro climatológico regional é marcado pela ausência de uma estação seca definida e por um clima subtropical úmido (MAACK, 1981), com média pluviométrica anual de 2.435,8 $\mathrm{mm}$, registrando até $3.465,4 \mathrm{~mm}$ junto às encostas mais elevadas da serra (VANHONI e MENDONÇA, 2008). Assim, devido às características topográficas e à concentração de altos valores de precipitação pluviométrica fortalecidos pelo bloqueio orográfico, a Serra do Mar Paranaense tem sido um cenário marcadamente afetado por movimentos de massa, destacando-se o evento ocorrido nos municípios de Antonina e Morretes em março de 2011.

O município de Antonina está localizado na porção leste do estado, sendo limítrofe a Baía de Antonina/Paranaguá (Figura 02). De acordo com Santos et al. (2006) identifica-se em seu perímetro as seguintes sub-unidades morfoesculturais: (a) Morros Isolados Costeiros; (b) Rampas de Pré-Serra e Serras Isoladas; (c) Serra do Mar e Blocos Soerguidos da Serra do Mar; (d) Planície Litorânea e Planícies Flúvio Marinhas. 


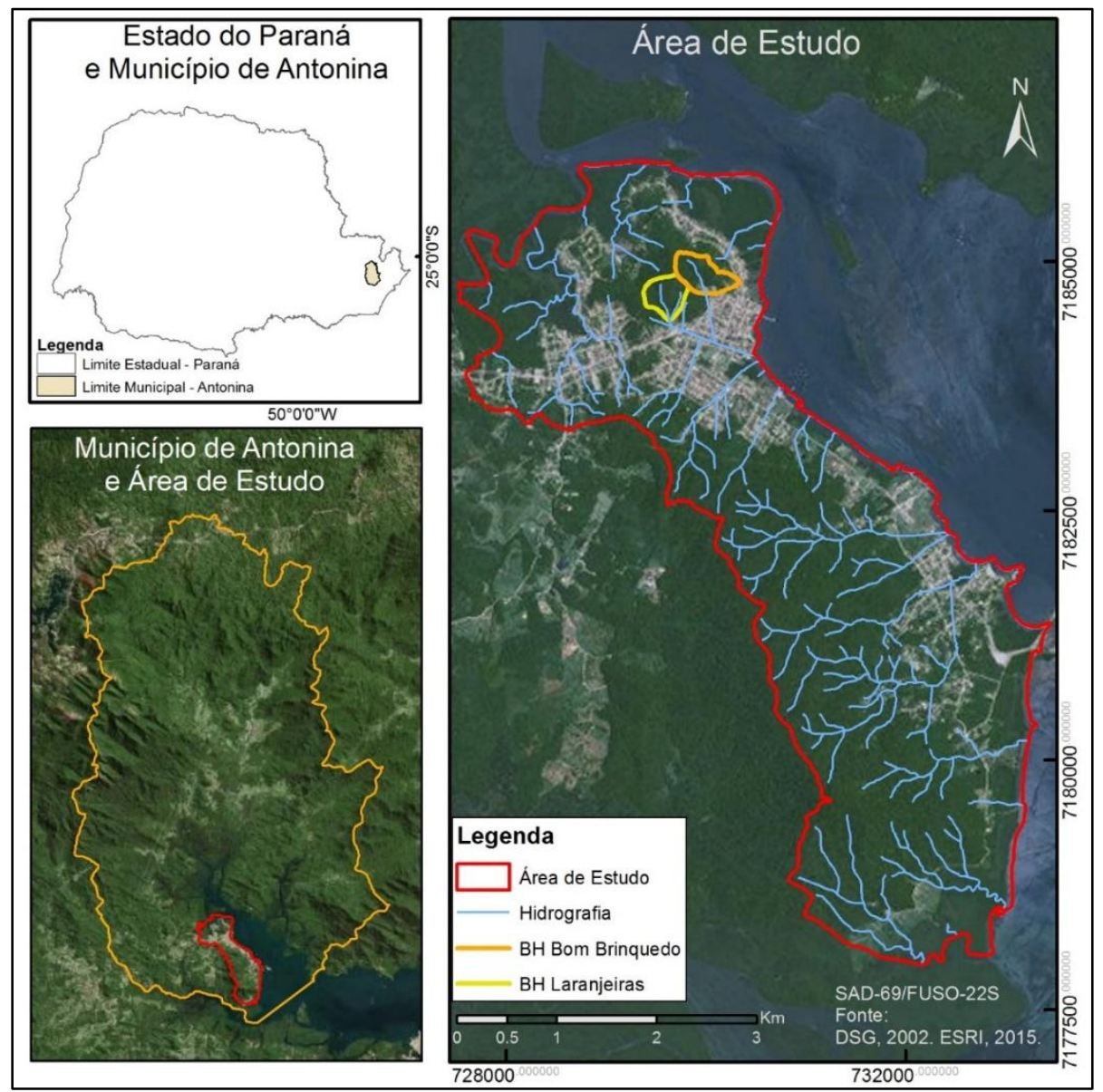

FIGURA 02: Mapa de localização das Bacias Hidrográficas do Bom Brinquedo e Laranjeiras, no perímetro urbano do município de Antonina (PR).

Fonte: DSG (2002), ESRI (2015).

Sua dimensão territorial é de $882,317 \mathrm{~km}^{2}$ e população de 18.891 habitantes, de acordo com dados do censo 2010 (IBGE, 2013). A ocupação urbana atual do município concentra-se junto à orla da Baía de Antonina, sobre a sub-unidade morfoescultural Planície Litorânea e Planícies Flúvio Marinhas e cercada por elevações dos Morros Isolados Costeiros. Sendo a primeira caracterizada por baixa dissecação com elevações variando entre 0 a 200 m.s.n.m., marcada por planícies de restingas e flúvio-marinhas, e a segunda por alta dissecação do relevo, com predominância de cimeiras alongadas, vales em "V" fechado, vertentes retilíneas e altitude variando entre 200 a 920 m.s.n.m. (MINEROPAR, 2006).

A área urbana do município, particularmente nas imediações do Morro do Bom Brinquedo, foi afetada por um evento de movimento de massa em 11 de março de 2011 (Figura 03). 0 evento foi desencadeado após uma precipitação pluviométrica de $98,6 \mathrm{~mm}$ para a data do evento e $263 \mathrm{~mm}$ entre o período de 01/03/2011 a 11/03/2011, conforme dados cedidos pelo Instituo Tecnológico Simepar. 


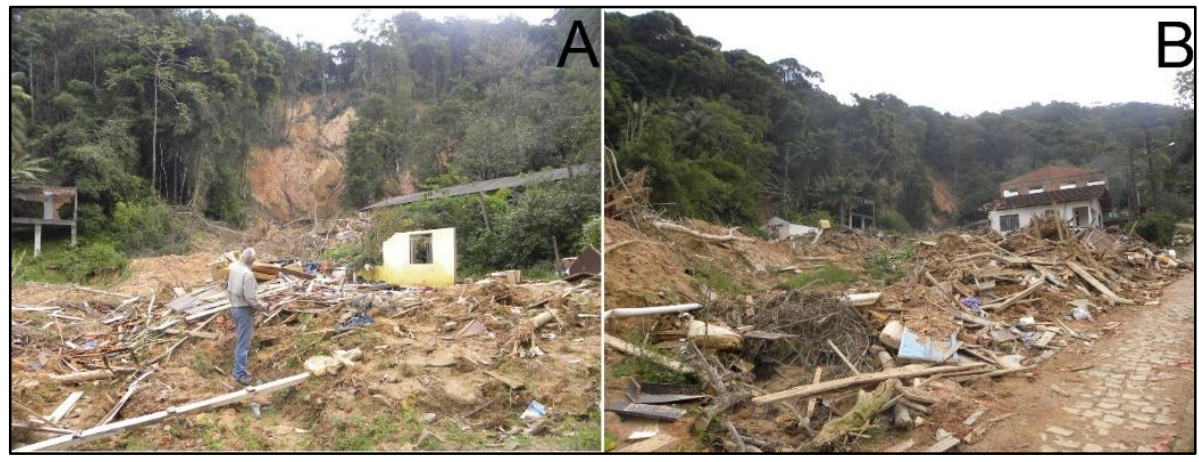

FIGURA 03: A e B: Escorregamentos ocorridos no Morro do Bom Brinquedo, em 11 de março de 2011, no município de Antonina (PR).

Fonte: Bianca Carvalho Vieira (2011).

Posteriormente ao evento destacam-se os trabalhos: MINEROPAR (2013), que realizou um mapeamento geológico detalhado do Morro do Bom Brinquedo, apontando a ocorrência de corpos graníticos, anfibolitos, quartzitos, sedimentos marinhos recortados por diques de diabásio porfirítico; Lopes (2013) obteve dados geotécnicos detalhados - ângulo de atrito, coesão, peso específico natural relativo e peso específico saturado relativo - de uma cicatriz resultante do evento, em uma das vertentes da mesma área, definida pelo autor de Bacia do Bom Brinquedo, objetivando correlacionar à espessura do solo e o nível freático com áreas de instabilidade na encosta.

\section{MATERIAL E MÉTODO}

Para realização da presente pesquisa fora selecionado a área urbana e periurbana do município de Antonina por meio do interflúvio dos Morros Isolados Costeiros. A definição deste perímetro se deu com base em mapeamento topográfico em escala 1:25.000 (DSG, 2002) e abrange uma área de $18,965 \mathrm{~km}^{2}$. Inserido neste perímetro foram selecionadas duas bacias hidrográficas, localizadas na porção setentrional do perímetro, sendo elas: Bacia Hidrográfica do Bom Brinquedo (BHBB), com uma área de $164.200 \mathrm{~m}^{2}$, e a Bacia Hidrográfica das Laranjeiras (BHL) que ocupa uma área de $171.800 \mathrm{~m}^{2}$.

O mapeamento das cicatrizes das bacias de drenagem foi executado sobre a imagem de satélite RapidEye, datada de 06 de agosto de 2011, composta por 5 bandas: 1 - Red, 2 Blue, 3 - Green, 4 -Red Edge e 5 - Near IR; possuindo resolução espacial de $5 \mathrm{~m}$. Sobre a imagem foram realizados testes de relação entre bandas buscando uma melhor identificação visual dos limites das cicatrizes, utilizando o software ENVI 4.8 e suas operações/técnicas Principal Components e Band Ratio.

Destarte, primeiramente, foi utilizada a técnica Principal Components, que tende a eliminar a alta correlação entre as bandas de um sensor, com pouca perda de informação, tendo seus princípios na estatística de análise de um grande número de variáveis (MENESES e ALMEIDA, 2012a).

Em seguida foi operada a técnica Band Ratio, que realiza a divisão de uma banda espectral da imagem por outra banda, buscando destacar uma determinada feição (MENESES e 
ALMEIDA, 2012b). A comparação com a composição RGB não foi contemplada, sendo a mesma já discutida e avaliada por Sestini e Florenzano (2004).

Com base no resultado da correlação de bandas fora selecionada a imagem com melhor expressão visual das cicatrizes e finalmente, foram demarcados os limites das cicatrizes sobre a imagem utilizando as ferramentas específicas no programa ArcMap 10.

Para concluir, no intuito de aferir os resultados, foram comparados os perímetros identificados sobre a imagem, com as intituladas "áreas de trânsito de movimentos de massa recente" e apresentadas na "Avaliação Geotécnica das Vertentes na Área Urbana de Antonina" em escala 1:5.000 (MINEROPAR, 2013).

\section{RESULTADOS E DISCUSSÃO}

As operações Principal Components e Band Ratio apresentaram resultados eficientes em relação à visualização das cicatrizes. Conforme apontam Almeida e Souza Filho (2004) e Sestini e Florenzano (2004), ambas as funções podem ser aplicadas em análise da cobertura vegetal, mostrando resultados eficientes na amostragem de diferentes tipos de cobertura e na identificação de cicatrizes.

Entretanto, o resultado expresso pela operação Principal Components foi inferior àqueles obtidos pela operação Band Ratio (Figura 04). Dentre as correlações de banda realizadas pela operação Band Ratio, verificou-se que o mais satisfatório se deu pela divisão da banda 5 (Near IR) pela banda 2 (Blue), sobremaneira para as cicatrizes localizadas na BHBB (Figura 5).

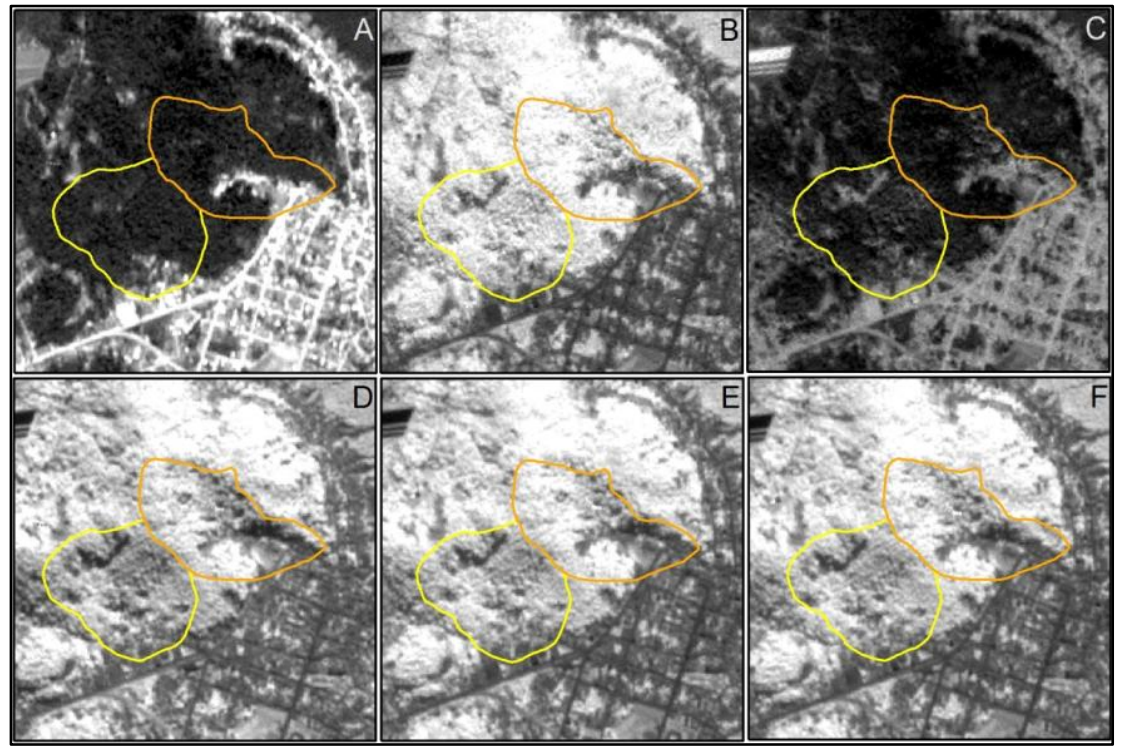

FIGURA 04: Exemplos das correlações de banda sobre a imagem RapidEye (os polígonos amarelo e alaranjado indicam as bacias hidrográficas). A) Operação Principal Components; B) Operação Band Ratio dividindo a Banda 5 pela Banda 4; C) Operação Band Ratio dividindo a Banda 4 pela Banda 5; D) Operação Band Ratio dividindo a Banda 5 pela Banda 1; E) Operação Band Ratio dividindo a Banda 5 pela Banda 3; F) Operação Band Ratio dividindo a Banda 5 pela Banda 2. Fonte: Autores (2013). 
Tendo como base o resultado da composição da Banda NEAR IR pela banda Blue, foram delimitados os perímetros das cicatrizes (Figura 05). Destaca-se que a definição das cicatrizes sobre a imagem não permitiu um melhor nível de detalhe, pois sua resolução espacial é originalmente de 6,5 metros, para cada uma das bandas; e após a ortorretificação atinge 5 metros de resolução, possibilitando uma precisão compatível com uma escala 1:25.000 (FELIX et al. 2009).

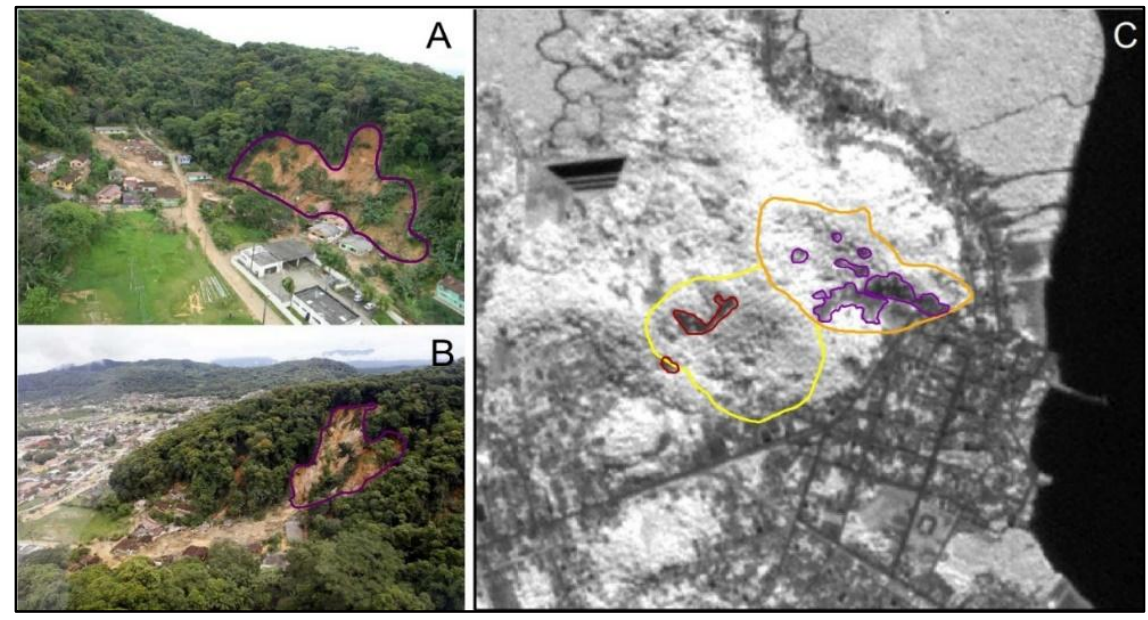

FIGURA 05: (A) Cicatrizes na BHBB; (B) Cicatrizes no setor Sudoeste na BHBB; (C) Operação Band Ratio dividindo a Banda 5 pela Banda 2 (amarelo e alaranjado indicam os perímetros das bacias). Fonte: a) Associação de Defesa do Meio Ambiente e do Desenvolvimento de Antonina (2011), b) Hedeson Alves do jornal Gazeta do Povo (2011), c) Ministério do Meio Ambiente (2011).

Conforme a Figura 06, as cicatrizes identificadas na imagem, quando comparadas àquelas mapeadas por MINEROPAR (2013), coincidiram parcialmente, permitindo considerar que a resolução da imagem não possibilita uma classificação em detalhe dos escorregamentos, sobremaneira àquelas que possam ter deslocados pequenas porções de vegetação.

Enquanto no mapa de cicatrizes da MINEROPAR (2013) são incluídas as zonas de arraste e deposição, no mapa a partir da imagem foi possível delimitar com maior clareza os terços superiores, assumindo-se como as zonas de ruptura dos escorregamentos. Assim, a diferença entre os dois mapeamentos pode influenciar diretamente no entendimento dos processos, pois, geralmente, somente a zona de ruptura é considerada quando se pretende avaliar o papel dos fatores condicionantes da desestabilização da encosta. 


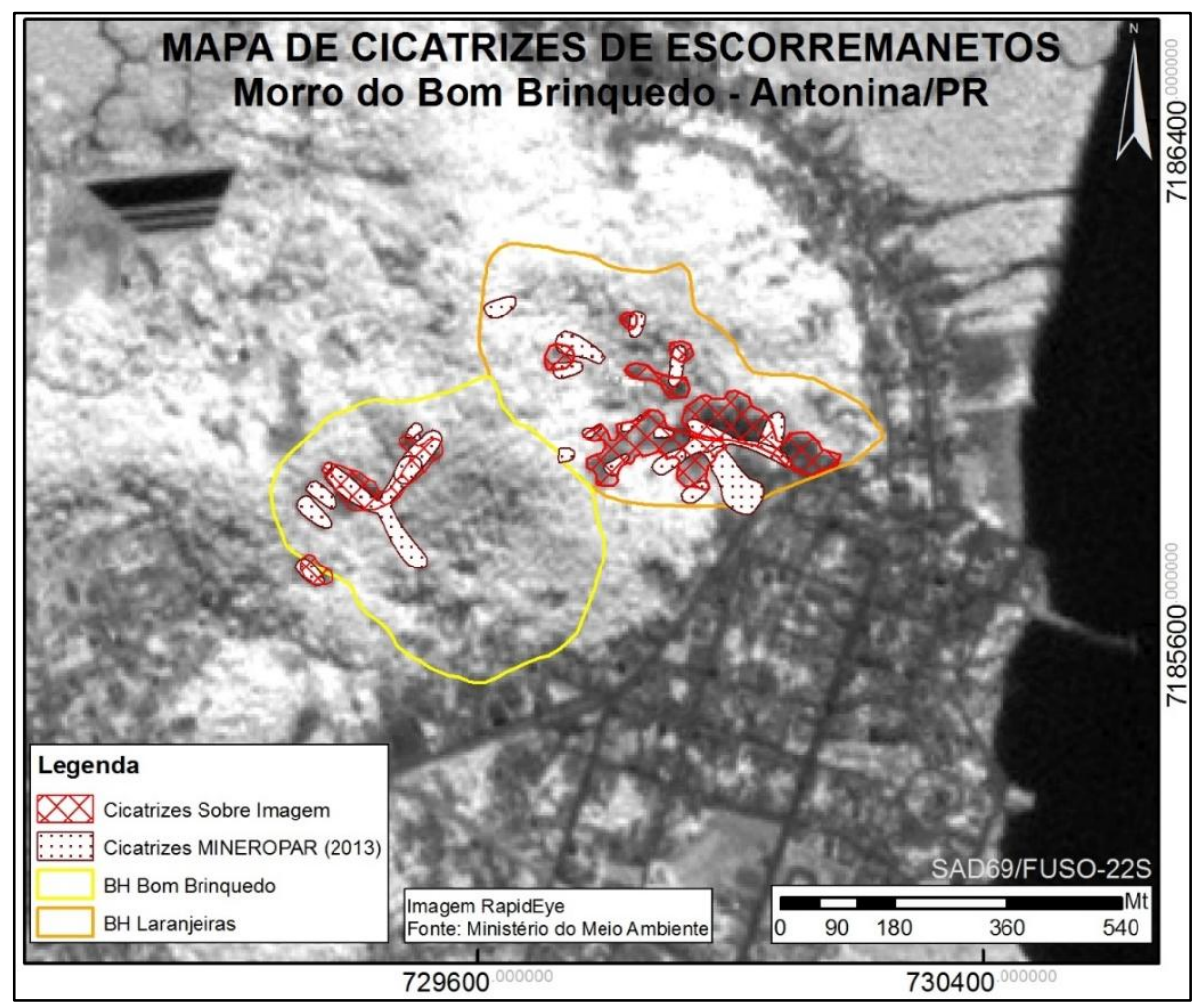

FIGURA 06: Mapa de Cicatrizes de Escorregamentos ocorridos em Março de 2011, nas Bacias Hidrográficas do Bom Brinquedo e Laranjeiras, município de Antonina (PR). Em vermelho os limites definidos neste trabalho.

Fonte: Ministério do Meio Ambiente (2011).

Considerando as dimensões das cicatrizes (Figura 07), de acordo com o mapa da MINEROPAR (2013), as áreas foram: $21.973,32 \mathrm{~m}^{2}$ (BHBB) e $13.041,48 \mathrm{~m}^{2}$ (BHL). Já por meio da imagem, as áreas foram $32.175,80 \mathrm{~m}^{2}$ (BHBB) e $9.488,31 \mathrm{~m}^{2}$ (BHL). Entende-se que as diferenças nas dimensões podem ser explicadas por: a) o mapeamento da MINEROPAR (2013) considerou além das zonas de ruptura, as zonas de transporte e de deposição; b) no mapeamento realizado com base na imagem identificou-se uma área maior de cicatrizes na BHBB no seu setor Sudeste.

Ressalta-se ainda que as cicatrizes identificadas não apresentaram um perímetro muito nítido, assumindo-se, desta forma, uma certa subjetividade, por parte do operador, sendo, portanto, necessária sua verificação em campo. Tal resultado, pode estar associado à relação entre a resolução espacial da imagem e a dimensão das feições (ex. depósitos). Desta forma, para uma identificação detalhada das cicatrizes nesta área, incluindo as zonas de ruptura, transporte e/ou arraste e deposição, é necessário o uso de produtos de sensoriamento remoto com melhor resolução espacial. 


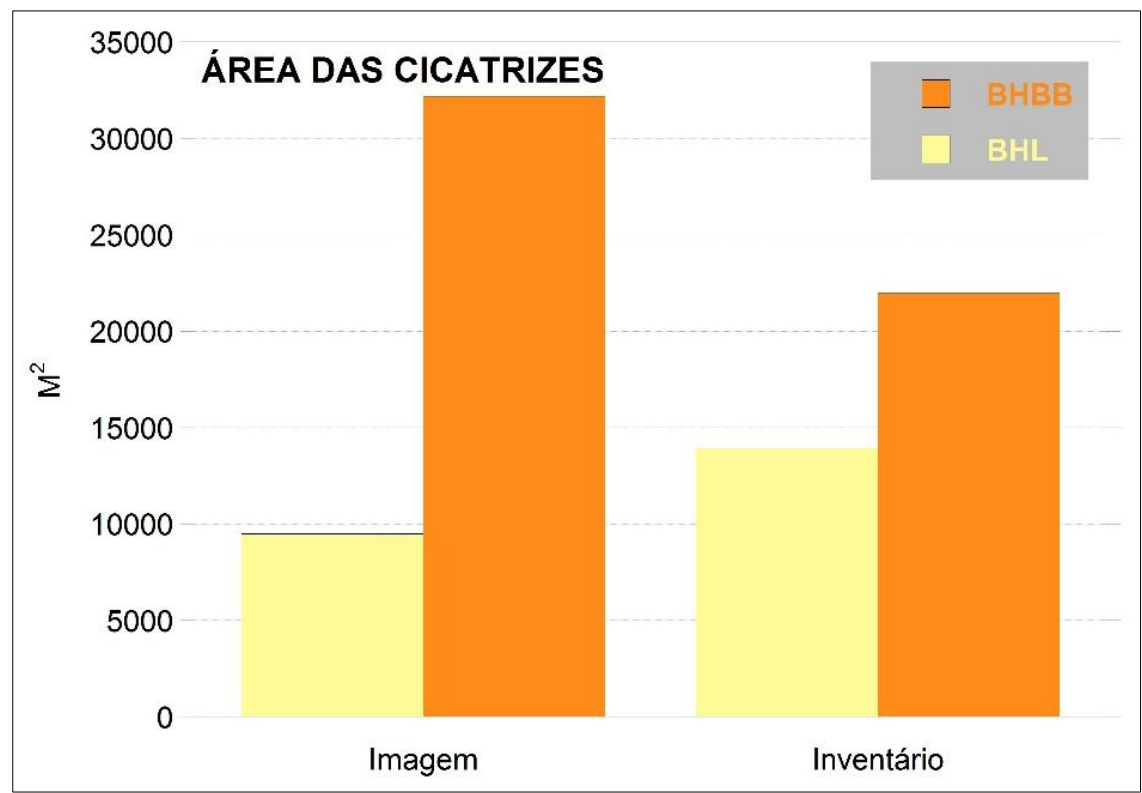

FIGURA 07: Área das cicatrizes $\left(\mathrm{m}^{2}\right)$ mapeadas no inventário da MINEROPAR (2013) e por meio da imagem nas bacias BHBB e BHL.

Fonte: Autores (2013).

$\mathrm{Na} \mathrm{BHL}$ as cicatrizes identificadas na imagem não permitiram selecionar com clareza duas feições apontadas como escorregamentos recentes. Já na BHBB a definição do perímetro das cicatrizes expressa certa generalização. Em ambas as análises, não foi definido um critério de identificação de uma cicatriz, que pode: a) incluir apenas a área de deslocamento de material, ou b) incluir a área fonte do material e toda a área afetada pelo seu percurso.

Portanto, diferentes procedimentos podem gerar diferentes níveis de imprecisão, assim como apontam Ardizzone et al. (2002), que realizaram uma comparação de diferentes inventários produzidos por 3 grupos, para uma mesma área (Bacia Staffora/Montes Apeninos, Itália). Os autores identificaram divergências de até $80 \%$ entre os mapas, considerando que as imprecisões são inerentes aos procedimentos metodológicos, pois os mesmos se apoiam em uma subjetividade interpretativa.

Em última análise, diferentes procedimentos utilizados no mapeamento das cicatrizes podem levar a uma interpretação equivocada dos inventários, a exemplo de um gestor público (ARDIZZONE, et al., 2002). Além disso, podem comprometer diretamente a qualidade dos resultados obtidos por diferentes ferramentas, como as análises estatísticas multivariadas que consideram as inter-relações entre vários fatores condicionantes dos escorregamentos (ex. forma da encosta e declividade) e a ausência ou presença de cicatrizes na paisagem. Finalmente, a qualidade do mapa de cicatrizes poderá também influenciar diretamente ou indiretamente na validação dos mapas de suscetibilidades gerados por modelos matemáticos em bases físicas. 


\section{CONCLUSÃO}

A discussão sobre os critérios para o mapeamento das cicatrizes é uma etapa importante para melhorar a produção de inventários. Os resultados sobre a temática devem ser avaliados, sobretudo porque há uma grande divergência dos critérios. Assim, quando utilizados para validação e/ou avaliação dos escorregamentos na paisagem podem gerar resultados distintos.

A aplicação da operação Band Ratio foi satisfatória para identificação visual das cicatrizes. Destaca-se, porém, que a resolução da imagem possibilitou a identificação visual da cicatriz, mas não permitiu uma clara definição de seus limites e depósitos correlatos, fazendo-se necessário um prévio reconhecimento da área.

Os resultados aqui expressos podem ser utilizados para mapeamentos em escala igual ou inferior a 1:25.000 e o método pode contribuir para uma primeira avaliação das cicatrizes, incluindo suas dimensões. Porém, possui certa limitação para informações de detalhe das feições (ex. tipologia de movimentos de massa). Para trabalhos futuros podem ser contempladas investigações, como por exemplo, a resposta espectral das distintas feições de um escorregamento.

Por fim, para a produção de um mapa de cicatrizes de movimentos de massa é importante uma avaliação prévia da dimensão destas feições e a sua área de abrangência, para definir a resolução espacial mais adequada ao mapeamento.

\section{AGRADECIMENTOS}

Os autores agradecem a CAPES (Processo BEX 5188/14-8) e a FAPESP (Processo 2014/101092) pelo auxílio financeiro e aos revisores anônimos.

\section{BIBLIOGRAFIA}

ALMEIDA, F.F. M., CARNEIRO, C.D.R. Origem e Evolução da Serra do Mar. In: Revista Brasileira de Geociências. Vol: 28, p.135-150, 1998.

ALMEIDA, T.I.R.; SOUZA FILHO, C.R. Principal component analysis applied to feature-oriented band ratios of hyperspectral data: A tool for vegetation studies. International Journal of Remote Sensing, England, 25:22, p. 5005-5023, 2004.

ARDIZZONE, F.; CARDINALLI, M.; CARRARA, A.; GUZZETTI, F.; REICHENBACH, P. Impact of mapping errors on the reliability of landslide hazard maps. Natural Hazards and Earth System Sciences 2: 3-14. 2002.

AVANZI, G. D., R. GIANNECCHINI and A. PUCCINELLI. The Influence of the geological and geomorphological settings on shallow landslides. An example in a temperature climate environment: the june 19, 1996 event in northwestern Tuscany (Italy). Engineering Geology 73: 215-228. 2004

AUGUSTO FILHO, O. Caracterização geológico-geotécnica voltada à estabilização de encostas: uma proposta metodológica. In: Conferência Brasileira Sobre Estabilidade de 
Encostas, 1, Rio de Janeiro. Anais... Rio de Janeiro: ABMS/ABGE/PUCRJ, 1992, v.2, p.721-733, 1992.

CROZIER, M. J. Landslides: causes, consequences and environment. New Zeland. 1986.

DSG. Diretoria de Serviços Geográficos. Carta Topográfica Antonina. Folha SG.22-X-D-II-4-SO. 2002.

ESRI. Environmental Systems Research Institute. ArcGis, ArcMap, Spatial Analyst, 3D Analyst. versão 10. 2014.

FELIX, I.M.; KAZMIERCZAK, M.L.; ESPINDOLA, G.M. RapidEye: a nova geração de satélites de Observação da Terra. Anais XIV Simpósio Brasileiro de Sensoriamento Remoto, Natal, Brasil, 25-30 abril 2009, INPE, p. 7619-7622.

FERNANDES, N.F; AMARAL, C. P. Movimentos de Massa: Uma Abordagem GeológicaGeomorfológica. In: GUERRA, A.J.T.; CUNHA, S.B. (org.) Geomorfologia e Meio Ambiente. Rio de Janeiro: Bertrand Brasil. 1996. pp. 123-194.

GUTHRIE, R. H. The effects of logging on frequency and distribution of landslides in three watersheds on Vancouver Island, Bristish Columbia. Geomorphology 43: 273-292. 2002.

GONTIJO-PASCUTTI, A.H.F., HASUI, Y., SANTOS, M., SOARES JÚNIOR, A. V., SOUZA, I. A. AS Serras do Mar e da Mantiqueira. In: HASUI, Y. CARNEIRO, C.D.R., ALMEIDA, F.F. M., BARTORELLI. A. (org.) Geologia do Brasil. São Paulo: Beca. 2012. p. 549-571.

GUIDICINI, G.; C. M. NIEBLE. Estabilidade de Taludes Naturais e de Escavação, Edgard Blücher: São Paulo. 2a Ed. 1983.

GUIMARÃES, R. F., D. R. MONTGOMERY, H. M. GREENBERG, N. F. FERNANDES, R. A. T. GOMES; O. A. P. CARVALHO JR. Parameterization of soil properties for a model of topographic controls on shallow landsliding: application to Rio de Janeiro. Engineering Geology, v. 69, p. 99-108, 2003.

GUNS, M.; VEERLE, V. Shifts in landslide frequency-area distribution after forest conversion in the tropical Andes. Anthropocene, 2014.

GUZZETTI, F.; MONDINI, A.C.; CARDINALI, M.; FIORUCCI, F.; SANTANGELO, M.; CHANG, K.T.; Landslide inventory maps: New tools for an old problem. Earth-Science Reviews 112: 42-66. 2012.

HUTCHINSON, J. N. Mass movement. Mass movement. R.W. Fairbridge. Reinhold Book, New York, pp. 688-700. 1968.

IBGE. Instituto Brasileiro de Geografia e Estatística. Cidades. Disponível em: $<w w w . i b g e . g o v . b r>$. Acesso em: 25 de janeiro de 2013.

LEE, S., U. CHWAE, M. KYUNGDUCK. Landslides susceptibility mapping by correlation between topography and geological structure: the Janghung area, Korea. Geomorphology 46: 149-162. 2002

LOPES, F.C.A. Avaliação da Influência da Distribuição Espacial da Espessura do Solo e do Nível Freático na Estabilidade de Encosta. 126p. Dissertação (Mestrado em Geografia) - Setor de Ciências da Terra, Universidade Federal do Paraná, 2013.

MAACK, R. Breves notícias sobre a Geologia dos Estados do Paraná e Santa Catarina. Arquivos de Biologia e Tecnologia, vol. II, art. 7, p. 66-154, 1947.

MAACK, R. Geografia Física do Estado do Paraná. 2 ed. Rio de Janeiro: José Olímpio. 1981. 
MENESES, P.R.; ALMEIDA, T. (a) Transformações por rotação espectral. In: (org.) Introdução ao Processamento de Imagens de Sensoriamento Remoto. Brasília: CNPQ. 2012a. p. 154-167.

MENESES, P.R.; ALMEIDA, T. (b) Aritmética de Bandas. In: (org.) Introdução ao Processamento de Imagens de Sensoriamento Remoto. Brasília: CNPQ. 2012b. p. 138-153.

MINEROPAR. Minerais do Paraná S.A. Carta Geomorfológica Curitiba-SG.22-X-D. Curitiba: MINEROPAR. 2006.

MINEROPAR. Minerais do Paraná S.A. Avaliação geotécnica de vertentes na área urbana de Antonina. Relatório Técnico. Vol. 1 e 2, 2013.

PEROTTO-BALDADIVIEZO, H. L., T. L. THUROW, C. T. SMITH, R. F. FISHER and X. B. WU. GisBased Spatial analysis and modelling for landslides hazard assessment in steeplands, southern Honduras. Agriculture, Ecosystems and Enviromental. 2004

RODERJAN, C. V.; GALVÃO, F.; KUNIYOSHI, Y. S.; HATSCHBACH, G. G. As unidades fitogeográficas do estado do Paraná, Brasil. Ciência e Ambiente. Santa Maria, n.24, p.75-92, 2002.

SANTOS, L. J. C.; OKA-FIORI, C.; CANALI N E, FIORI A P, SILVEIRA, C. T.; SILVA, J. M. F.; ROSS, J. L. S.; Mapeamento Geomorfológico do Estado do Paraná. Revista Brasileira de Geomorfologia, v.7, n.2, p. 3-11, 2006.

SESTINI, M.F.; FLORENZANO, T.G. Caracterização de Cicatrizes de Deslizamento por Processamento de Dados TM Landsat em Caraguatatuba-SP. Revista do Instituto GeológicoUSP. Sér. Cient., São Paulo, v. 4, n. 2, p. 57-69, 2004.

SILVEIRA, C. T.; FIORI, A. P.; FERREIRA, A. M.; FELIPE, R. S.; KEPEL FILHO, J. L.; FOLADOR, R. M.; COSTA, L.C. Análise do Fator de Segurança da Estabilidade das Vertentes na Bacia do Rio Jacareí, Serra do Mar Paranaense. Revista Brasileira de Geomorfologia, v. 13, p. 287-297, 2012.

VANHONI, F., MENDONÇA, F. O Clima do Litoral do Estado do Paraná. Revista Brasileira de Climatologia, v.3/4, p.49-53, 2008.

VAN WESTEN, C. J. Application of Geographic Information System to Landslide Hazard Zonation, ITC Publication, Enschede, The Netherlands, pp. 245. 1993.

VAN WESTEN, C. J. Geo-information tools for landslide risk assessment: an overview of recent development In Landslides: Evaluation and Stabilization. Taylor \& Francis Group, Rio de Janeiro: 39-53. 2004.

VARNES, D. J. Slope movement types and processes. In S. KRIZEK (ed) Slope movement types and processes, Washington, pp. 11-33. 1978.

ZAIDAN, R.T.; FERNANDES, N.F. Zoneamento de Suscetibilidade a Escorregamentos Rasos em Encostas Aplicado à Bacia de Drenagem Urbana do Córrego do Independência - Juiz de Fora (MG). In: Revista Brasileira de Geomorfologia. v.10, no 2, p. 57-76, 2009.

ZARUBA, Q., MENCL, V. Landslides and their control. Amsterdam: Elsevier. 205p. 1976.

Artigo submetido em

Artigo aceito em
04/06/2015

$07 / 07 / 2015$ 